Iavorska I. V. Oxygen-dependent oxidation of proteins in the pathogenesis of spleen injury caused by acute blood loss, complicated by ischema-reperfusion of the limb and the efficiency of their correction by carbacetam. Journal of Education, Health and Sport. 2020;10(12):372-381. eISSN 2391-8306. DOI http://dx.doi.org/10.12775/JEHS.2020.10.12.037

https://apcz.umk.pl/czasopisma/index.php/JEHS/article/view/JEHS.2020.10.12.037

https://zenodo.org/record/4894992

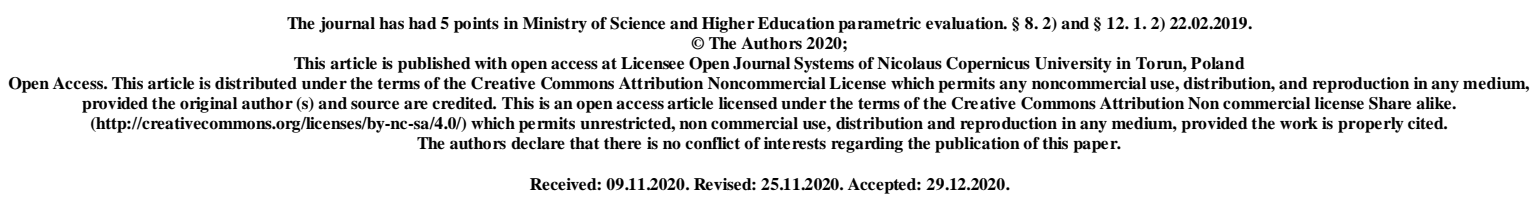

UDK 612.015.348:64.41-02:616./37.8-005.4-007.272-085.214.2]-09209

\title{
OXYGEN-DEPENDENT OXIDATION OF PROTEINS IN THE PATHOGENESIS OF SPLEEN INJURY CAUSED BY ACUTE BLOOD LOSS, COMPLICATED BY ISCHEMA-REPERFUSION OF THE LIMB AND THE EFFICIENCY OF THEIR CORRECTION BY CARBACETAM
}

\section{V. Iavorska}

\section{Horbachevsky Ternopil National Medical University Ministry of Health of Ukraine}

\begin{abstract}
Activation of free radical processes is one of the key mechanisms of acute blood loss and ischemic-reperfusion syndrome. The spleen plays an important role in adaptivecompensatory processes during the blood loss. However, the state of oxidative modifications of proteins (OMP) in the spleen has not been studied enough. There are no data on the effectiveness of carbacetam in these conditions, that showed a pronounced protective effect on the enzyme link of the spleen antioxidant protection.

Objective of research: to study the role of oxygen-dependent protein oxidation in the pathogenesis of spleen involvement during and after acute blood loss complicated by limb ischemia-reperfusion, and the effectiveness of its correction with carbacetam.

Materials and methods. The experiments were performed on 108 nonlinear male rats weighing 200-220 g. All experiments were made using thiopental-sodium anesthesia. In separate groups of animals were simulated limb ischemia-reperfusion and acute blood loss as well as these combined injuries. In a separate group, the detected disorders were corrected
\end{abstract}


with carbacetam. After 1 and 2 hours, as well as after 1, 7 and 14 days in the spleen of the experimental animals was determined the content of oxidative modifications of protein (OMP). The spleen was taken for additional investigation and the content of neutral $\left(\mathrm{OMP}_{370}\right)$ and basic $\left(\mathrm{OMP}_{430}\right)$ was determined in its homogenate.

Results. Modeling of acute blood loss, complicated by ischemia-reperfusion of the limb, contributed to the increasing of the processes of uncontrolled oxidative modification of proteins in the spleen. The content of $\mathrm{OMP}_{370}$ rised significantly in the groups of animals, in which only ischemia-reperfusion of the limb or acute blood loss were simulated beginning from $2 \mathrm{~h}$ of the experiment. The content of $\mathrm{OMP}_{430}$ exceeded the base level in these experimental groups after 1 and 14 days. Violations of the studied indicators reached a maximum after 1 day, decreased to day 14, but did not reach the level of control group. Carbacetam had a protective effect on the intensity of $\mathrm{OMP}_{370-430}$ after 7 and 14 days of its usage, which puts carbacetam in a line of promising agents of complex therapy of spleen disturbances caused by acute blood loss and ischemic-reperfusion syndrome.

Conclusions: Complication of acute blood loss by ischemia-reperfusion of the limb causes intensification of OMP in the spleen, that, compared with the control is an increase in the content of aldehyde and ketone derivatives of neutral and basic nature throughout the whole experiment with its maximal level at day 1 . The use of carbacetam significantly reduces the intensity of OMP in the spleen compared to the group of animals that had no additional drug correction.

Key words: acute blood loss; ischemia-reperfusion of the limb; spleen, oxidative modification of proteins; carbacetam.

Introduction. Acute blood loss is one of the key causes of death during firearms conflicts. Due to the growing frequency of local armed conflicts and terrorist attacks, the problem of life saving of the wounded with massive acute blood loss both on the battlefield and in hospitals is an urgent problem of modern medicine [1].

To save the wounded on the battlefield, between the effective measures were the timely use of a tourniquet, which completely stops blood circulation in the affected limb, along with urgent evacuation to the hospital stage, so that the duration of complete ischemia of the limb does not exceed 2 hours [2]. However, recently more and more often the data of clinical observations and experimental studies state that the imposition of a tourniquet for two hours significantly worsens the course of acute blood loss [5]. At the base of the detected disorders are hypoxia, formation of reactive oxygen species (ROS) and, as a consequence - 
the activation of lipid peroxidation process, which causes significant disorders in the internal organs and is a background for the development of multiorgan dysfunction [2, 5].

It is known that during the oxidative stress ROS can cause harm to all structures of biological membranes. At the same time there is also a stimulation of oxidative modification not only of membranous phospholipids, but also proteins, that leads to the change in the physico-chemical properties of cells [3, 12].

Uncontrolled oxidative modification of proteins (OMP) causes fragmentation of proteins, their denaturation, as well as the formation of primary amino acid radicals, which then enter into secondary interaction with neighboring amino acid residues, which in general creates a complex picture of the damaging effect of OMP on the protein macromolecules. All of these leads to the loss of the biological activity of proteins and disruption of metabolic, particularly regenerative processes [9].

In our previous studies of the acute blood loss complicated by ischemia-reperfusion of the limb, it was found that the activation of lipid peroxidation (LPO) in the spleen [11], an organ that plays an important role in the development of adaptive-compensatory processes in a process of acute blood loss $[4,6]$. However, OMP of the spleen in such conditions was studied insufficiently. There are no data on the effect of carbacetam on the processes of OMP, that has a pronounced antioxidant effect in such cases [11].

Objective of research: to study the role of oxygen-dependent protein oxidation in the pathogenesis of spleen involvement in acute blood loss complicated by limb ischemiareperfusion, and the effectiveness of its correction with carbacetam.

Materials and methods. The experiments were performed on 108 nonlinear male rats weighing 200-220 g. All experiments were performed in accordance with the rules of the European Convention for the Protection of Vertebrate Animals Used for Experimental and Other Scientific Purposes (European Convention, 1986).

All animals were divided into five groups: control and four experimental (6 rats per group). All interventions were performed under thiopepntal-sodium anesthesia $\left(40 \mathrm{mg} / \mathrm{kg}^{-1} \mathrm{of}\right.$ the body weight). In the first experimental group, the animals were modeled ischemiareperfusion of the limb by applying the tourniquet proximally on the left leg for 120 minutes A strip of elastic harness "SWAT-T" (USA) $10 \mathrm{~mm}$ wide was used. This tourniquet has minimal negative impact on the underlying tissues and provides permanent complete ischemia during the time of experiment [16]. In the second experimental group, modeled acute blood loss of $20-22 \%$ of the circulating blood volume via crossing the femoral vein. In the third experimental group, these injuries were combined. In the fourth experimental group, to 
animals with acute blood loss, complicated by ischemia-reperfusion of the limb, for correction purposes additionally intraperitoneally injected carbacetam (L.M. Litvinenko Institute of Physical-Organic Chemistry and Coal Chemistry of the National Academy of Sciences of Ukraine, Kyiv) at a dose of $5 \mathrm{mg}$ per kilogram of the animal weight. [11].

Under conditions of thiopental - sodium anesthesia, the animals of the first, second and third experimental groups were removed from the experiment after 1 and 2 hours, as well as after 1, 7 and 14 days, the animals of the fourth experimental group - after 7 and 14 days. In the control group, the animals were only anesthetized using an equivalent dose of thiopental - sodium, and a tourniquet was applied without cessation of blood flow and they were subsequently removed from the experiment after 2 hours.

For the additional research spleen was taken, and in its homogenate was determined the content of OMP using the method of I. F Meshchishen [7]. The method is based on the fact that the final products of free radical protein oxidation can quantitatively react with 2,4dinitrophenylhydrazine with subsequent formation of 2,4-dinitrophenylhydrazones that have a special absorption spectrum. Aldehyde and ketone derivatives that had a neutral character were registered at $370 \mathrm{~nm}$, and those with the basic character - at $430 \mathrm{~nm}$. The probability of differences between the control and experimental groups was assessed using the nonparametric Mann-Whitney test.

Research results and their discussion. Analysis of the OMP370 content in the spleen showed that after modeling only the ischemia-reperfusion of the limb, the indicator at $1 \mathrm{~h}$ of the experiment compared with the control statistically significantly increased (by $31.9 \%, \mathrm{p}$ $<0.05)$ and reached a maximum after 1 day (2.17 times, $\mathrm{p}<0.05)$. By the day 14 , the level decreased and did not differ significantly from the control level ( $p>0.05$ ). After modeling of acute blood loss, the indicator in all terms of the experiment was statistically significantly higher than the control ( $\mathrm{p}<0.05)$ with a maximum also after 1 day (3.38 times, $\mathrm{p}<0.05)$. After 14 days, the indicator exceeded the control by 2.68 times $(\mathrm{p}<0.05)$. Complications of acute blood loss with ischemia-reperfusion of the limb were accompanied by even greater deviations. The maximum level of the studied indicator was observed after day 1 . At this period, the content of OMP370 was 4.40 times higher than the control level. After 14 days, the indicator decreased, but continued to remain 3.38 times higher than in the control $(\mathrm{p}$ $<0,05)$.

Comparison of experimental groups showed that after $1 \mathrm{~h}$ of the experiment, the indicator significantly prevailed in experimental groups 2 and 3 compared with experimental group 1 (respectively by 25.8 and $50,0 \%, \mathrm{p}_{1-2}<0,05 ; \mathrm{p}_{1-3}<0,05$ ). and subsequently revealed a 
pattern according to which with increasing severity of the disorder, the content of $\mathrm{OMP}_{370}$ in the spleen was statistically significantly higher $\left(\mathrm{p}_{1-2}<0,05 ; \mathrm{p}_{1-3}<0,05 ; \mathrm{p}_{2-3}<0.05\right)$.

Table 1 - The content of $\mathrm{OMP}_{370}\left(\mathrm{mmol} \cdot \mathrm{g}^{-1}\right)$ in the spleen after acute blood loss complicated by ischemia-reperfusion of the limb ((Me (LQ; UQ) - median (lower and upper quartiles))

\begin{tabular}{|c|c|c|c|c|c|}
\hline \multirow{2}{*}{$\begin{array}{l}\text { Experimental } \\
\text { group }\end{array}$} & \multicolumn{5}{|c|}{ Period of reperfusion } \\
\hline & $1 \mathrm{~h}$ & $2 \mathrm{~h}$ & Day 1 & Day 7 & Day 14 \\
\hline \multicolumn{6}{|c|}{ Control $=0,47(0,45 ; 0,50)(n=6)$} \\
\hline $\begin{array}{l}\text { Group } 1 \\
\text { Ischemia } \\
\text { reperfusion }\end{array}$ & $\begin{array}{l}0,62^{*} \\
(0,60 ; 0,67) \\
(n=6)\end{array}$ & $\begin{array}{l}0,73^{*} \\
(0,71 ; 0,76) \\
(n=6)\end{array}$ & $\begin{array}{l}1,02^{*} \\
(0,91 ; 1,11) \\
(\mathrm{n}=6)\end{array}$ & $\begin{array}{l}0,63^{*} \\
(0,54 ; 0,68) \\
(n=6)\end{array}$ & $\begin{array}{l}0,56 \\
(0,50 ; 0,64) \\
(n=6)\end{array}$ \\
\hline $\begin{array}{l}\text { Group2 } \\
\text { Bleeding }\end{array}$ & $\begin{array}{l}0,78^{*} \\
(0,69 ; 0,91) \\
(\mathrm{n}=6)\end{array}$ & $\begin{array}{l}1,13^{*}(1,09 ; \\
1,22) \\
(\mathrm{n}=6)\end{array}$ & $\begin{array}{l}1,59^{*} \quad(1,52 ; \\
1,74) \\
(n=6)\end{array}$ & $\begin{array}{l}1,48^{*} \quad(1,43 ; \\
1,53) \\
(\mathrm{n}=6)\end{array}$ & $\begin{array}{l}1,26^{*} \quad(1,18 ; \\
1,32) \\
(\mathrm{n}=6)\end{array}$ \\
\hline $\begin{array}{l}\text { Group } 3 \\
\text { Ischemia- } \\
\text { reperfusion+ } \\
\text { bleeding }\end{array}$ & $\begin{array}{l}0,93^{*} \quad(0,86 ; \\
0,97) \\
(n=6)\end{array}$ & $\begin{array}{l}1,43^{*} \quad(1,38 ; \\
1,53) \\
(n=6)\end{array}$ & $\begin{array}{l}2,07^{*} \quad(1,92 ; \\
2,20) \\
(n=6)\end{array}$ & $\begin{array}{l}1,90^{*} \quad(1,72 ; \\
2,00) \\
(n=6)\end{array}$ & $\begin{array}{l}1,59^{*} \quad(1,45 ; \\
1,66) \\
(n=6)\end{array}$ \\
\hline $\mathrm{p}_{1-2}$ & $<0,05$ & $<0,05$ & $<0,05$ & $<0,05$ & $<0,05$ \\
\hline $\mathrm{p}_{1-3}$ & $<0,05$ & $<0,05$ & $<0,05$ & $<0,05$ & $<0,05$ \\
\hline $\mathrm{p}_{2-3}$ & $>0,05$ & $<0,05$ & $<0,05$ & $<0,05$ & $<0,05$ \\
\hline
\end{tabular}

Notes. Here and in Table. 2:

1. * - differences relative to the control group that are statistically significant $(\mathrm{p}<0.05)$;

2. $\mathrm{p}_{1-2}$ - the probability of differences between experimental groups 1 and 2;

3. $\mathrm{p}_{1-3}$ - the probability of differences between experimental groups 1 and 3;

4. $\mathrm{p}_{2-3}$ - the probability of differences between experimental groups 2 and 3.

At the same time, the content of $\mathrm{OMP}_{430}$ in the spleen (Table 2) after modeling only ischemia-reperfusion of the limb after $1 \mathrm{~h}$ compared with the control showed almost no significant change $(\mathrm{p}<0,05)$. However, starting from $2 \mathrm{~h}$ of the experiment, the indicator increased significantly, reaching a maximum after 1 day $(89,6 \%, p<0,05)$, then decreased and reached the level of the control group by the day $14(\mathrm{p}>0,05)$.

After modeling of acute blood loss, the content of $\mathrm{OMP}_{430}$ in the spleen in all periods of observation exceeded the level of control: after 1 hour - by $44.8 \%$, after 2 hours - by 83.6\%, after 1 day -2.78 times, after 7 days -2.61 times, after 14 days -2.08 times $(\mathrm{p}<0,05)$. Even greater changes occurred after acute blood loss complicated by ischemia-reperfusion of the limb. Compared to the control, the indicator increased by $65.7,98,5 \%, 3,49,3,05$ and 2,78 times, respectively ( $\mathrm{p}<0,05)$. Comparison of experimental groups showed that after $1 \mathrm{~h}$ of the experiment in groups 2 and 3 the content of $\mathrm{OMP}_{430}$ in the spleen was significantly higher 
than in experimental group 1 (respectively by 34,7 by $54,2 \%, \mathrm{p}_{1-2}<0,05, \mathrm{p}_{1-3}<0,05$ ). Similarly, in groups 2 and 3 the indicator was statistically significantly higher than in the experimental group 1 after 2 hours and after 7 days of the experiment $\left(\mathrm{p}_{1-2}<0,05, \mathrm{p}_{1-3}<0,05\right)$. However, after 1 and 14 days it was found that with increasing severity of disorder, the content of $\mathrm{OMP}_{430}$ was statistically significantly higher $\left(\mathrm{p}_{1-2}<0,05, \mathrm{p}_{1-3}<0,05, \mathrm{p}_{2-3}<0,05\right)$.

Table 2 - The content of $\mathrm{OMP}_{430}\left(\mathrm{mmol} \cdot \mathrm{g}^{-1}\right)$ in the spleen after acute blood loss complicated by ischemia-reperfusion of the limb (Me (LQ; UQ) - median (lower and upper quartiles))

\begin{tabular}{|c|c|c|c|c|c|}
\hline \multirow{2}{*}{$\begin{array}{l}\text { Experimental } \\
\text { group }\end{array}$} & \multicolumn{5}{|c|}{ Period of reperfusion } \\
\hline & $1 \mathrm{~h}$ & $2 \mathrm{~h}$ & Day 1 & Day 7 & Day14 \\
\hline \multicolumn{6}{|c|}{ Контроль $=0,67(0,63 ; 0,71)(\mathrm{n}=6)$} \\
\hline $\begin{array}{l}\text { Group } 1 \\
\text { Ischemia } \\
\text { reperfusion }\end{array}$ & $\begin{array}{l}0,72 \\
(0,69 ; 0,76) \\
(n=6)\end{array}$ & $\begin{array}{l}0,88^{*} \\
(0,84 ; 0,93) \\
(\mathrm{n}=6)\end{array}$ & $\begin{array}{l}1,27^{*} \\
(0,23 ; 1,35) \\
(\mathrm{n}=6)\end{array}$ & $\begin{array}{l}1,08^{*} \\
(0,98 ; 1,14) \\
(\mathrm{n}=6)\end{array}$ & $\begin{array}{l}0,81 \\
(0,73 ; 0,84) \\
(\mathrm{n}=6)\end{array}$ \\
\hline $\begin{array}{l}\text { Group2 } \\
\text { Bleeding } \Gamma\end{array}$ & $\begin{array}{l}0,97^{*} \\
(0,90 ; 1,07) \\
(\mathrm{n}=6)\end{array}$ & $\begin{array}{l}1,23^{*} \\
(1,12 ; 1,32) \\
(\mathrm{n}=6)\end{array}$ & $\begin{array}{l}1,86^{*} \\
(1,79 ; 1,94) \\
(\mathrm{n}=6)\end{array}$ & $\begin{array}{l}1,75^{*} \\
(1,56 ; 1,89) \\
(\mathrm{n}=6)\end{array}$ & $\begin{array}{l}1,39^{*} \\
(1,26 ; 1,52) \\
(\mathrm{n}=6)\end{array}$ \\
\hline $\begin{array}{l}\text { Group } 3 \\
\text { Ischemia- } \\
\text { reperfusion+ } \\
\text { bleeding }\end{array}$ & $\begin{array}{l}1,11^{*} \\
(0,98 ; 1,15) \\
(n=6)\end{array}$ & $\begin{array}{l}1,33^{*} \\
(1,28 ; 1,43) \\
(n=6)\end{array}$ & $\begin{array}{l}2,34^{*} \\
(2,22 ; 2,44) \\
(n=6)\end{array}$ & $\begin{array}{l}2,05^{*} \\
(1,91 ; 2,22) \\
(n=6)\end{array}$ & $\begin{array}{l}1,86^{*} \\
(1,81 ; 1,91) \\
(n=6)\end{array}$ \\
\hline $\mathrm{p}_{1-2}$ & $<0,05$ & $<0,05$ & $<0,05$ & $<0,05$ & $<0,05$ \\
\hline $\mathrm{p}_{1-3}$ & $<0,05$ & $<0,05$ & $<0,05$ & $<0,05$ & $<0,05$ \\
\hline $\mathrm{p}_{2-3}$ & $>0,05$ & $>0,05$ & $<0,05$ & $>0,05$ & $<0,05$ \\
\hline
\end{tabular}

Administration of carbacetam during the period of 7 days led to a significant decrease in the content of $\mathrm{OMP}_{370}$ in the spleen (Fig. 1) compared with animals without corrective treatment $(25,3 \%, \mathrm{p}<0,05)$. The indicator decreased even more after the use of carbacetam during 14 days (by 35,8\%, p<0,05). Similarly, carbacetam was effective according to the content of $\mathrm{OMP}_{430}$ in the spleen (Fig. 2). After 7 days of drug usage the indicator decreased by $15.6 \%$ (p<0,05), after 14 days - by $20.4 \%$ (p <0,05).

Thus, under the conditions of modeling only ischemia-reperfusion of the limb, we showed for the first time that in the spleen, despite of the lipid peroxidation processes activation, there is also an activation of OMP processes, which showed by an increase in aldehyde and ketone derivatives of neutral and basic character, starting from the 2 hours of the experiment withb its maximum on the $1^{\text {st }}$ day. However, until day 14 , studied indicators 
returned to the control level and the same was shown for the content of lipoperoxidation products [11].

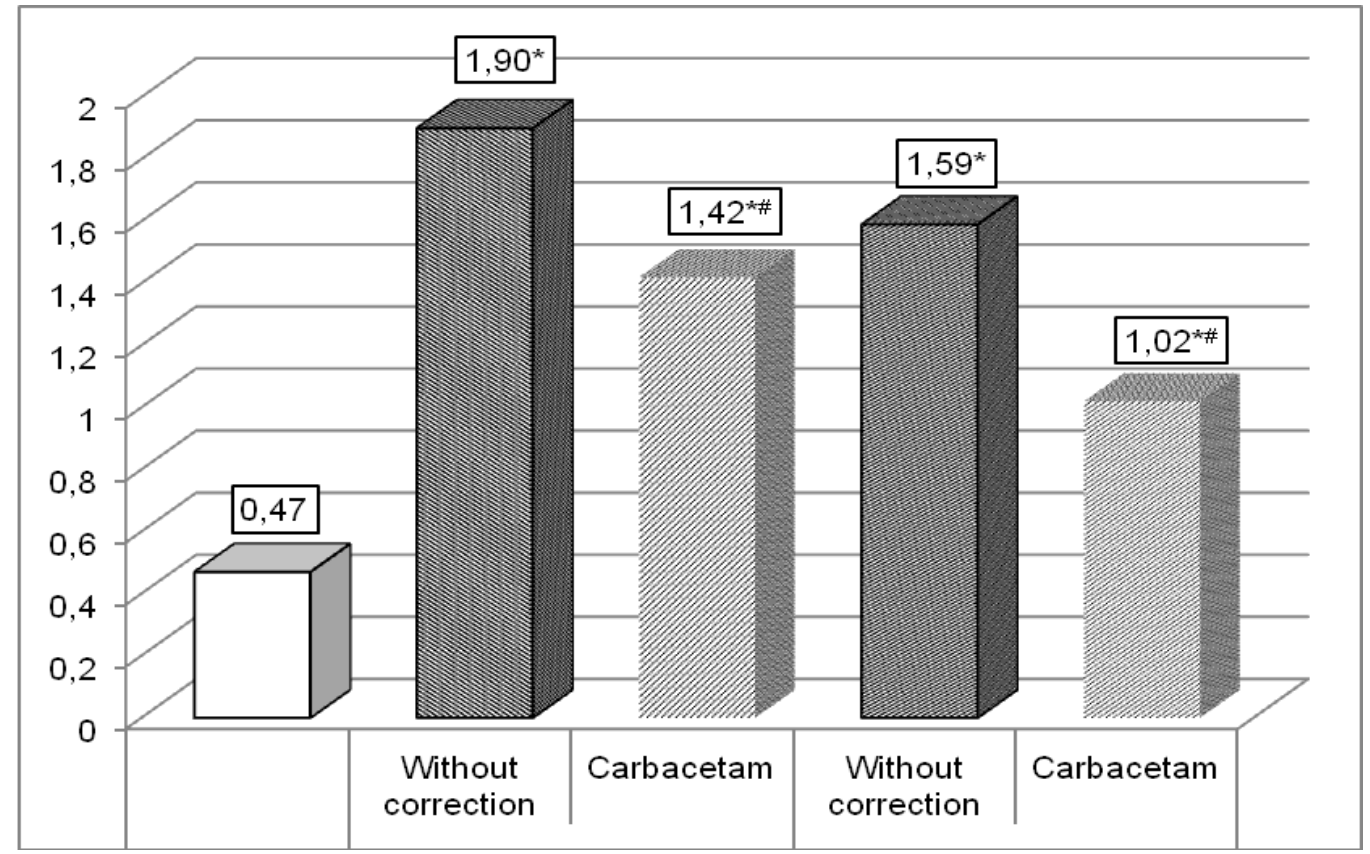

Figure 1 - The effect of carbacetam on the content of $\mathrm{OMB}_{370}$ in the spleen $\left(\mathrm{mmol} \cdot \mathrm{g}^{-1} 1\right)$ after acute blood loss complicated by ischemia-reperfusion of the limb

Note. Here and in Fig. 2: * - differences relative to the control group are statistically significant, $\mathrm{p}<0,05 ;{ }^{\#}$ - differences relative to the group without correction are statistically significant, $\mathrm{p}<0,05)$.

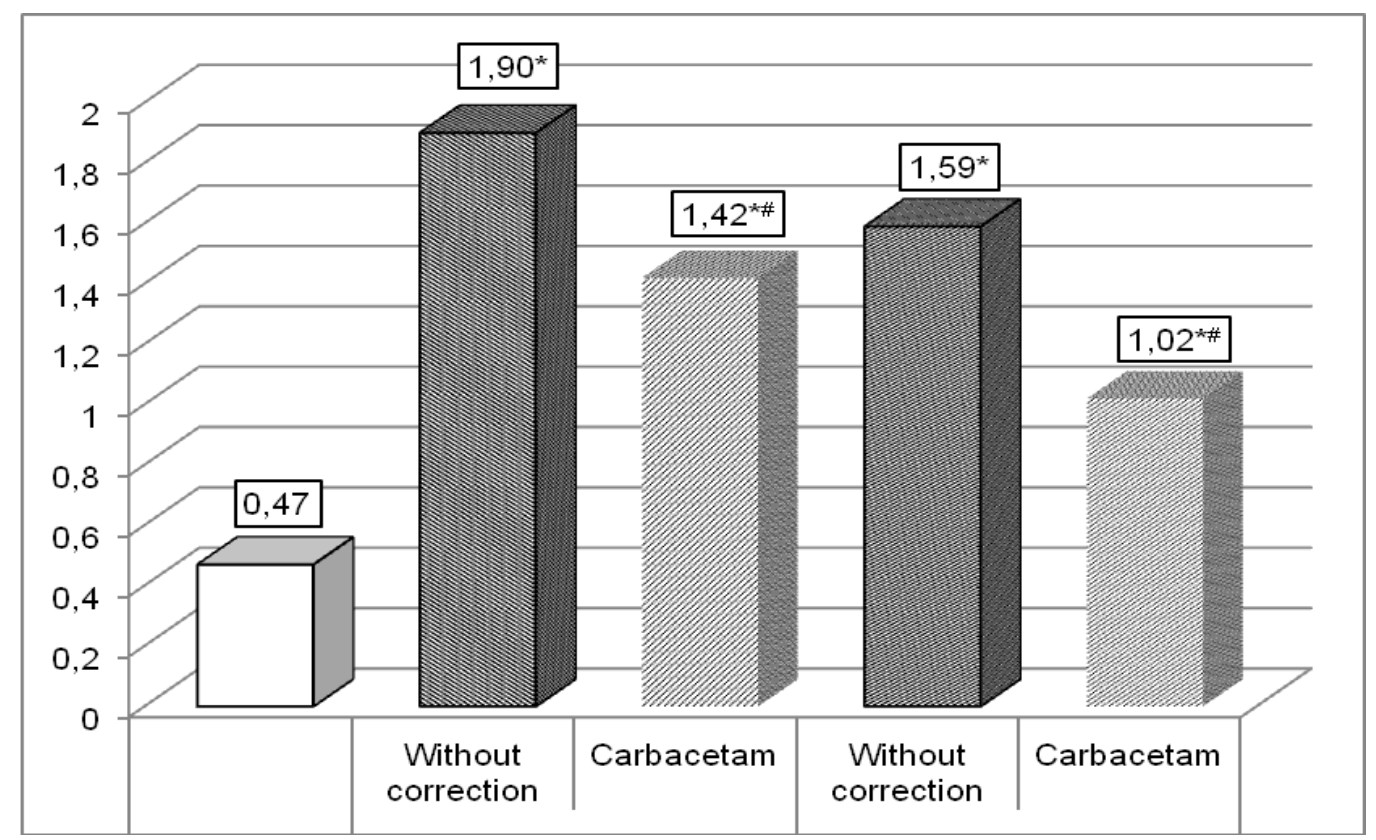

Figure 2 - The effect of carbacetam on the content of $\mathrm{OMB}_{430}$ in the spleen $\left(\mathrm{mmol} \cdot \mathrm{g}^{-1}\right)$ after acute blood loss complicated by ischemia-reperfusion of the limb. 
Received result indicates that the ischemia of the limb that lasts for 2 hours during the reperfusion period causes disorders that are within the scope of homeostatic regulation of the body. This fact is confirmed by studies of other authors, who found that irreversible changes in the soft tissues of the limb occur after 6 hours of total ischemia [14]. After modeling blood loss, the detected violations occurred from starting from $1 \mathrm{~h}$ of the experiment and did not subside until 14 days. Their maximum was also observed after 1 day, which indicates on the depletion of antioxidant protection with the inclusion of additional sanogenic mechanisms and generally corresponds to the body's response to acute blood loss $[2,8,10]$. However, we found even higher level of accumulation of OMP products after complication of acute blood loss by limb ischemia-reperfusion, and in this case the content of aldehyde and ketone derivatives of neutral character exceeded in the group in which only acute blood loss was simulated starting from $2 \mathrm{~h}$ of experiment, and derivates of the main character after 1 and 14 days. The obtained result indicates that pathogenic mechanisms associated with temporary activation of lipid peroxidation processes, at the base of which, in both conditions - limb ischemia-reperfusion and acute blood loss, is the accumulation of AFO, they are layered on each other and have a mutual burden effect. Taking into account that the pathogenic role of OMP products is caused by their genomic and cytotoxicity, the ability to cause cell death by apoptosis or necrosis [13], their accumulation in the spleen can adversely affect the main functions of the organ, including hematopoietic and immune. This fact also indicates the possibility of more pronounced systemic disorders in conditions of acute blood loss, when a tourniquet was used to stop the bleeding, even during a relatively safe period of application for 2 hours.

Using carbacetam for correction in acute blood loss complicated by ischemiareperfusion of the limb significantly reduced the intensity of OMP in the spleen after 7 and 14 days of usage. The drug has proven its antioxidant ability, leading to the protection from peroxidation not only of lipids but also of proteins of cell membranes in the spleen tissues. Although the indicators did not return to the control level, obtained result indicates the feasibility of carbacetam usage to reduce the manifestations of OMP in the spleen.

Conclusions. 1. Complication of acute blood loss by ischemia-reperfusion of the limb causes intensification of OMP in the spleen, which in comparison with the control, is shown as an increase in the content of aldehyde and ketone derivatives of neutral and basic nature throughout the whole term of experiment with a maximum on day 1. During this period, the indicators were significantly higher, compared with the group, in which only acute blood loss was modeled. 
2. Using of carbacetam at a dose of $5 \mathrm{mg} \cdot \mathrm{kg}^{-1}$ significantly reduces the intensity of OMP in the spleen compared with animals that had no corrective treatment for 7 and 14 days, indicating the prospects of the drug in the complex treatment of acute bleeding complicated by limb ischemia-reperfusion.

Prospects for further research. In the future, it is advisable to consider the pathogenic effect of acute blood loss and ischemia-reperfusion of the limb on the spleen as well as the corrective effect of carbacetam at the morphological level and to consider the indicators of hemogram and immune protection

\section{References}

1. Gaida I.M., Badyuk M.I., Sushko Y.I. Features of the structure and course of modern combat injury in servicemen of the Armed Forces of Ukraine. Pathology. 2018. 15, №. 1. P. $73-76$.

2. Gorban I.I .Influence of acute blood loss complicated by ischemia-reperfusion of the limb on the antioxidant-prooxidant balance of the liver and its correction by carbacetam. Achievements of clinical and experimental medicine. 2020. № 2. P. 93-100.

3. Ena L.M., Chayalo P.P., Hristoforova A.M. Mechanisms of action and prospects of application of drugs for metabolic therapy and ischemic heart disease. Ukr. cardiol. magazine. 2006. № 5. P. 100-106.

4. Lobov V.V., Nacharov Yu. V., Zubakhin A.A. Hematopoietic function of the spleen in the posthemorrhagic period. Journal of the NSU. Series: biology, clinical medicine. 2006. Vol. 4 Issue. 2. P. 78-83.

5. Maximov R.V., Gudima A.A., Sidorenko V.M. Dynamics of the balance of antioxidant-prooxidant mechanisms in the internal organs under the influence of arterial tourniquet and limb reperfusion. Hospital surgery. Magazine named after L.Ya.Kovalchuk. 2017. № 1 / P 37—44.

6. Morpho-functional organization of the spleen of laboratory animals (literature review) / O.V. Avilova, O.O. Prykhodko, O.O. Trach, O.S. Yarmolenko, L.V. Boomeister. The world of medicine and biology. 2017. № 1 (59). P. 175-179.

7. Meshchishen I.F. Method for determining the oxidative modification of plasma proteins (serum). Bukovin. med. bull 1998. Vol. 2, №1. P. 156-158.

8. Violation of the content of restored glutathione in the lungs of rats on the background of acute blood loss complicated by ischemia reperfusion of the limb, and their correction with carbacetam / O.V. Stakhiv, A.A. Gudyma, I.V. Korda, Yu. V. Uglyar. Medical and clinical chemistry. 2020. Vol. 22. № 3. P. 74-80. 
9. Prokhorov D.V., Pritulo O.A. Medium-mass molecules as a marker of endogenous intoxication in patients with microbial eczema. Dermatovenereol., Cosmetology., Sexopathol. 2001. № 1 (4). P. 95-97.

10. Shatsky V.V., Hudyma A.A., Fedonyuk L.Ya. Dynamics of antioxidant-prooxidant balance of cortical and cerebral layers of the kidney after acute blood loss complicated by ischemia-reperfusion of the limb, and its correction by carbacetam. Achievements of clinical and experimental medicine. 2019. № 4. P. 144-153.

11. Iavorska I.V., Hospodarskyy I.Ya. Dynamics of activity of lipid peroxidation processes in the spleen under the influence of acute blood loss complicated by ischemiareperfusion of the limb, and its correction by carbacetam. Achievements of clinical and experimental medicine. 2020. № 4. P. 178-185.

12. Aerobic fitness is associated with cardiomyocyte contractile capacity and endothelial function in exercise training and detraining / O.J.Kemi, R.M.Haram, U.Wisloff [et al.] Circulation. 2004. Vol. 109, № 23. P. 2897-2904.

13. Berlett B. S., Stadtman E. R. Protein Oxidation and Aging, Disease, and Oxidative Stress. TheJournalofBiologicalChemistry. 1997. 272, № $33 . \quad$ P. 20313-20316. http://dx.doi.org/10.1074/ jbc.272.33.20313

14. Blaisdell F. W. The pathophysiology of skeletal muscle ischemia and the reperfusion syndrome: a review. Cardiovascular Surgery. 2002. Vol. 10, № 6. P. 620-630.

15. New tourniquet device concepts for battlefield hemorrhage control / J. F. Jr. Kragh, C. Murphy, M. A. Dubicket al. U.S. Army Medical Department Journal. 2011. P.3848.

16. Tourniquets and occlusion: the pressure of design / P. L. Wall, D. C. Duevel, M. B. Hassan [et al.]. MilMd. 2013.Vol.178 (5) .P. 578-587. 